$2^{\text {nd }}$ July 2016

Global Marketing Conference Hong Kong

\title{
Internal market orientation \\ leveraging firm performance via internal success
}

Qionglei Yu, Ph.D

Canterbury Christchurch University, UK

Bradley R. Barnes, Ph.D

Sheffield Business School, UK 


\section{Content of the presentation}

- Introduction

- Background: Internal market orientation

- Conceptual Development

- Research Methodology

- Findings and Results

- Discussion and implications 


\section{Introduction}

- This research is proposed to examine how IMO could be employed as a tool to facilitate better employer-employee relation from the internal market perspective.

-The research posits that IMO leads to high employee commitment, retention and better interdepartmental relationship, hence firm performance.

-The notion of internal customers and internal marketing which are derived from marketing has not received enough research attention in employee management.

-The pressing matter to include both individual and departmental level internal customers so as to retain high firm performance. 


\section{Theoretical Background}

-External?

-Market transaction

-Internal?

-Social and economic exchange between individuals

and groups (Homans, 1958; Blau, 1964; Lawler, 2001;

Aryee, 2002; Zafirovski, 2003) 


\section{Internal Relationships}

- Mintzberg (1979) classified internal and external partnerships. Internal partnerships are referred to as groups functioning within the organisation.

- Gronroos (1981) pointed out that 'everyone' has a customer within the organisation.

- Heskett et al. (1994); Ballantyne (1995,1997, 2000); Dibb and Simkin (2000). 


\section{Who are internal customers?}

- Front-line employees facing external customers?

- Every employee in the company?

- Employees receiving services or products from internal suppliers? 


\section{Why IMO}

- Specific and clearly defined IMO provides management a checklist to follow.

- Lack of empirical support that examine IMO's impact on employee commitment, employee retention and interdepartmental relationship and firm performance.

- Second-order construct of Internal Market Orientation

- Internal information generation

- Internal information communication

- Responsiveness to information 


\section{Conceptual Framework}

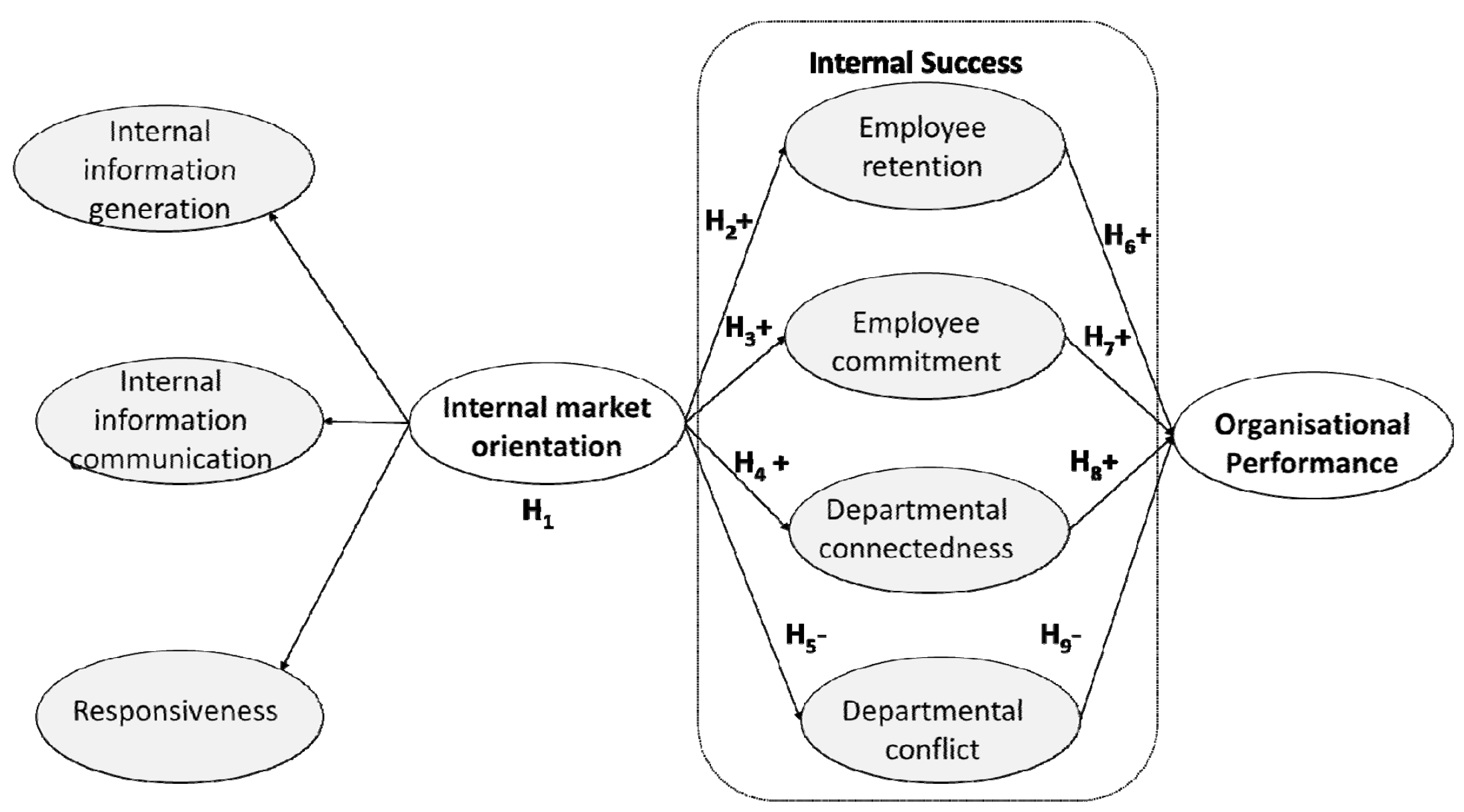




\section{Research Methods}

-Interviews, pre-test, and survey

-A survey questionnaire is employed to collect data from Chinese companies. 275 usable cases were collected.

-Three participants in each company were recruited to complete different parts of the survey. They are the HR personnel, Mid-manager and marketing manager.

- Overall, 825 respondents from 275 companies (48\% service and $52 \%$ non-service). 


\section{Results and Findings}

Table: Estimation results of the Structural Model $\mathrm{GFI}=.906, \mathrm{CFI}=.951, \mathrm{RMSEA}=.053, \chi^{2} / \mathrm{DF}=1.77$

$\begin{array}{lllllc}\text { Path } & \text { Hypotheses } & \text { Sign } & \text { Estimates } & \text { P-value } & \text { Supported? } \\ \mathrm{IMO} \rightarrow \mathrm{ER} & \mathrm{H}_{2} & + & .526 & * * * & \text { Yes } \\ \mathrm{IMO} \rightarrow \mathrm{EC} & \mathrm{H}_{3} & + & .492 & * * * & \text { Yes } \\ \mathrm{IMO} \rightarrow \mathrm{DCD} & \mathrm{H}_{4} & + & .539 & * * * & \text { Yes } \\ \mathrm{IMO} \rightarrow \text { DCF } & \mathrm{H}_{5} & - & -.246 & * * * & \text { Yes } \\ \text { ER } \rightarrow \text { PERF } & \mathrm{H}_{6} & + & .272 & \text { n.s. } & \text { No } \\ \text { EC } \rightarrow \text { PERF } & \mathrm{H}_{7} & + & .104 & * * & \text { Yes } \\ \text { DCD } \rightarrow \text { PERF } & \mathrm{H}_{8} & + & .077 & * & \text { Yes } \\ \text { DCF } \rightarrow \text { PERF } & \mathrm{H}_{9} & + & .028 & \text { n.s. } & \text { No }\end{array}$

$* * *$ Regression is significant at 0.001 level $(p<0.001)$

$* *$ Regression is significant at 0.01 level $(p<0.01)$

*Regression is significant at 0.05 level $(p<0.05)$ 


\section{Implications}

- Findings suggest managers would be wise to understand the benefits that IMO can offer in terms of cultivating the internal environment.

- By focusing on the needs and wants of their internal customers, organisations can successfully plan and implement strategies to inspire their employees.

- We strongly recommend that organisations which operate with centrally planned and controlled mechanisms should look to eliminate such constraints. 


\section{Future Research Direction}

- Examine the relationship between IMO and performance across cultures.

- Include cultural variables, in order to explore how these may also influence such internal relationships.

- Undertake longitudinal research designs to assess causality between constructs. 


\section{Thank You}

Lei (Qionglei Yu, Qionglei.yu@Canterbury.ac.uk) Bradley (Bradley R. Barnes, b.r.barnes@Shu.ac.uk) 